\title{
Stability Analysis for Yield and its Components in Pigeonpea [Cajanus cajan (L.) Mill sp.] Under Rainfed Conditions
}

\author{
Ramesh*, S. Muniswamy and B. Praveenkumar \\ Agricultural Research Station, Aland Road, Kalaburagi-585101 Karnataka, India \\ *Corresponding author
}

\begin{tabular}{|c|c|}
\hline & A B S T R A C T \\
\hline Keywords & \multirow{4}{*}{$\begin{array}{l}\text { An Investigation was carried out to examine the stability analysis of the twenty genotypes } \\
\text { of pigeonpea including check BSMR-736, during kharif-2012, } 2013 \text { and } 2014 \text { under } \\
\text { rainfed condition at the Agricultural Research Station, Kalaburagi, Karnataka, India. } \\
\text { Highly significant differences among varieties were observed for all the characters except } \\
\text { pod bearing length }(\mathrm{cm}) \text {, number of pods per plant and seed yield } \mathrm{kg} / \mathrm{ha} \text {. The variance due } \\
\text { to Genotype x Environmental (GxE) interaction found significant for the characters like } \\
\text { number of seeds per pod and pod length. All the traits under the study except for } 100 \text { seed } \\
\text { weight showed significant differences in different environment. The variance due to } \\
\text { pooled deviation was highly significant for all the traits except primary branches, number } \\
\text { of seeds per pod and pod length under study which reflect considerable variability in the } \\
\text { material. Out of } 20 \text { genotypes the genotype ICP-13270 were found to be a stable for pod } \\
\text { length and ICP } 9691 \text { and ICP } 12654 \text { are on par with check for seed yield kg/ha across the } \\
\text { environments for rainfed conditions. }\end{array}$} \\
\hline $\begin{array}{l}\text { Genotype x } \\
\text { Environment } \\
\text { (G x E), } \\
\text { pigeonpea, } \\
\text { stability. }\end{array}$ & \\
\hline Article Info & \\
\hline $\begin{array}{l}\text { Accepted: } \\
\text { 12 April } 2017 \\
\text { Available Online: } \\
10 \text { May } 2017\end{array}$ & \\
\hline
\end{tabular}

\section{Introduction}

Pigeonpea [Cajanus cajan (L.) Millsp.] is commonly known in India, as redgram or arhar or tur or thogari. It is a short-lived perennial shrub in which plants may grow for about five years and turn into small trees. India is considered as the native of pigeonpea (Vander and Messen, 1980) because of its natural genetic variability available in the local germplasm and the presence of its wild relatives in the country.

It is an important grain legume that originated in the Indian sub-continent. It is now grown in many parts of the world including Southern Africa particularly the region encompassing Kenya, Mozambique, Malawi and Southern Tanzania (Hogh Jensen et al., 2007).
This region is considered as a secondary centre of diversity for pigeonpea, it is a short lived perennial shrub in which plants may grow for about five years and turn into small trees. It is an often cross pollinated crop (20$70 \%)$ with diploid $(2 \mathrm{n}=2 \mathrm{x})$ chromosome number of 22 and the estimated size of pigeonpea genome packed in 11 chromosomes is $858 \mathrm{Mbp}$ (Greilhuber and Obermayer, 1998).

Pigeonpea is the important grain legume which occupies a major place in dietary requirement. It is cultivated in varied agro climatic conditions ranging from moisture stress and input starved conditions to irrigated conditions. Pigeonpea breeders look forward 
for widely adapted genotypes responsive to input intensive as well as input deficient agriculture in order to enhance production and productivity of the crop. Selection and yield testing are the two major phases of varietal development and the later one is highly influenced by the locations and years of testing. The magnitude of $\mathrm{G} \times \mathrm{E}$ interaction and its components has a direct bearing on the environmental domain of the varieties to be recommended for commercial cultivation. With this back ground the present study was undertaken under rainfed situation in three locations to identify stable genotypes of Pigeonpea for seed yield and its component traits.

\section{Materials and Methods}

The present experiment material comprised of 20 genotypes of pigeonpea including check BSMR-736 received from Indian Institute of Pulse Research Kanpur. The trials were conducted in a randomized block design with two replications in three season viz., kharif2012, 2013 and 2014 grown under rainfed condition. The plot size of two rows each with $4 \mathrm{~m}$ length was followed with spacing of 75 $\mathrm{cm}$ between rows and $25 \mathrm{~cm}$ between the plants observations were recorded on five randomly selected plants in each replication in each environment in respect of 12 different metric characters viz., days to 50 per cent flowering, days to maturity, plant height $(\mathrm{cm})$, number of primary branches per plant, number of secondary branches per plant, pod bearing length, number of seeds per pod, pod length $(\mathrm{cm})$, number of pods per plant, seed yield per plant, 100- seed weight (g)and seed yield $\mathrm{kg} / \mathrm{ha}$. Stability analysis was carried out by using the stability model proposed by Eberhart and Russell (1966).

\section{Results and Discussion}

Pooled ANOVA for stability of different characters (Eberhart and Russell, 1966) are given in table 1. Genotypic differences pooled over environments were significant for the nine characters except pod bearing length $(\mathrm{cm})$, number of pods per plant and seed yield $\mathrm{kg} / \mathrm{ha}$. Variance due to environments was significant for all the characters except 100 seed weight. Variance due to $\mathrm{G} \times \mathrm{E}$ was significant for three characters viz., number of seeds /pod and pod length (cm).However, further partitioning of genotype $\mathrm{x}$ environmental interaction as per Eberhart and Russell's (1966) model indicated that, Environmental + (Genotype x Environment) interaction was significant for plant height, primary branches, number of seeds per pod, pod length, seed yield per plant and seed yield $\mathrm{kg} / \mathrm{ha}$. Environment linear component was significant for all the traits except 100 seed weight. Whereas, $\mathrm{G} \times \mathrm{E}$ (linear) interaction was non-significant for most of the characters except number of seeds per pod and pod length $(\mathrm{cm})$, which indicated differential response of genotypes to the environments. As regard to pooled deviation (nonlinear portion of variance), which is unpredictable portion of $\mathrm{G} \times \mathrm{E}$ interaction was significant for all the characters except primary branches, number of seeds per pod and pod length $(\mathrm{cm})$ under study. This demonstrated that genotypes respond differently to variation in environmental condition. The results are in accordance with Shoran et al., (1981), Balakrishna and Natarajratnam (1989) and Sawargaokar et al., (2011). In contrast, significant GxE (linear) for number of seeds per pod and 100 seed weight was observed by Muthiah and Kalaimagal (2005). Ghodke (1992) obtained non significant G x E for majority of the traits.

The genotype ICP 16309 showed minimum number of days to $50 \%$ flowering (91.33 days) while, Bahar required maximum number of days to $50 \%$ flowering (139.66 days) and population mean over three environments was 117.65 days. All the genotypes showed non-significant value for 
regression coefficient and deviation from regression. The genotypes viz., ICP 16309, ICP 14832, TJT 501, BSMR 736 (check), ICP 12654, ICP 6971, ICP 6049, TTB 7, RVK 284 and ICP 9691 were found to have lesser mean value than population mean with non significant bi and $\mathrm{S}^{2} \mathrm{~d}_{\mathrm{i}}$ values. None of the genotypes had stable performance. ICP 16309 was the earliest to days to $50 \%$ flowering. The genotypes which require minimum number of days to $50 \%$ flowering are more desirable. So, ICP 16309, ICP 14832, TJT 501, BSMR 736 (check) and RVK 284 had the regression value more than unity, indicating its suitability to favourable environments. The genotypes viz., ICP 12654, ICP 6971, ICP 6049, TTB 7 and ICP 9691 had the regression value less than unity, it indicates suitable for poor environments. These findings are in accordance with Patel et al., (2009), Vannirajan (2007) who identified genotypes with average responsiveness and also genotypes with higher environmental sensitivity.

The genotype ICP 16309 showed minimum number of days to maturity (144.66 days) while, Bahar required maximum number of days to maturity (194.83 days) and population mean over three environments was 173.13 days. All the genotypes showed nonsignificant value for regression coefficient and deviation from regression. The genotypes viz., ICP 16309, TJT 501,ICP 14832, ICP 6971, BSMR 736 (check), TTB 7, ICP 13270, ICP 12654,ICP 13304, RVK 284 and ICP 6049 were found to have lesser mean value than population mean with non significant bi and $S^{2} d_{i}$ values. None of the genotypes had stable performance. ICP 16309 was the minimum number of days to maturity. The genotypes which are early are more desirable. So, ICP 16309, TJT 501, ICP 14832 and ICP 13270 had the regression value more than unity, it indicates specifically adapted to favourable environments. The genotypes viz., ICP 6971, BSMR 736 (check), TTB 7, ICP
12654, ICP 13304, RVK 284 and ICP 6049 had the regression value less than unity, it indicates specifically adapted to unfavourable environments. The results are in accordance with Singh (1984) and Thanki et al., (2010) identified genotypes having average and above average stability for this trait. Sreelakshmi et al., (2010) obtained three stable genotypes (ICPL 98008, ICPHL 49792 and ICP 77303) for maturity.

The genotype ICP 8700 showed maximum plant height $(163.00 \mathrm{~cm})$ while, ICP 16309 minimum plant height $(113.33 \mathrm{~cm})$ and population mean over three environments was $143.43 \mathrm{~cm}$. All the genotypes showed nonsignificant value for regression coefficient and deviation from regression. The genotypes viz., ICP 8700, NDA 1,TTB 7,ICP 13673, Bahar, ICP 3451, ICP 9691, ICP 6668, ICP 13304,ICP 13270and RVK 284 were found to have higher mean value than population mean with non significant bi and $S^{2} d_{i}$ values. None of the genotypes had stable performance. ICP 8700 was the highest plant height. The genotypes which are tall plant height are more desirable. So, ICP 8700, TTB 7, ICP 13673, Bahar and ICP 3451 had the regression value more than unity, it indicates specifically adapted to favourable environments. The genotypes viz., NDA 1, ICP 9691, ICP 6668, ICP 13304, ICP 13270and RVK 284 had the regression value less than unity, it indicates specifically adapted to unfavourable environments. Similar results were obtained by Sawargaokar et al., (2011), identified stable genotypes for this trait. In contrast Ghodke (1992) obtained non singnificant G x E for this trait.

The genotype ICP 3451 showed maximum number of primary branches (13.94) while, ICP 16309 minimum numbers of primary branches (8.88) and population mean over three environments was 11.47. All the genotypes showed non-significant value for regression coefficient and deviation from 
regression. The genotypes viz., ICP 3451, ICP 12654, ICP 9691,NDA 1, MAL 13, ICP 8700, ICP 13673, ICP 6049, ICP 6668 were found to have higher mean value than population mean with non significant bi and $\mathrm{S}^{2} \mathrm{~d}_{\mathrm{i}}$ values. None of the genotypes had stable performance. ICP 3451 was the higher number of primary branches. The genotypes viz., ICP 12654, ICP 9691, ICP 8700, ICP 6049, ICP 6668 and BSMR 736 (check) had the regression value more than unity, indicating its suitability to favourable environments. The genotypes viz., ICP 3451, NDA 1, MAL 13 and ICP 13673 had the regression value less than unity, it indicates suitable for poor environments.

The genotype ICP 6668 showed maximum number of secondary branches (11.44) while, ICP 13270 minimum numbers of secondary branches (3.16) and population mean over three environments was 6.52. All the genotypes showed non-significant value for regression coefficient and deviation from regression. The genotypes viz., ICP 6668, ICP 6971, ICP 9691, ICP 12654, ICP 13673, ICP 3451, NDA 1, BSMR 736 (check) and ICP 13304 were found to have higher mean value than population mean with non significant bi and $S^{2} d_{i}$ values. None of the genotypes had stable performance.

ICP 6668 found higher number of secondary branches. The genotypes viz., ICP 6668, ICP 9691, ICP 12654, ICP 13673, BSMR 736 (check) and ICP 13304 had the regression value more than unity, indicating its suitability to favourable environments. The genotypes viz., ICP 6971, ICP 3451 and NDA 1 had the regression value less than unity, it indicates suitable for poor environments.

The genotype TJT 501 showed higher pod bearing length (40.22) while, ICP 12654 lesser pod bearing length (24.83) and population mean over three environments was 31.13. All the genotypes showed non- significant value for regression coefficient and deviation from regression. The genotypes viz., TJT 501, RVK 284, ICP 8700, ICP 6049,ICP 14832, BSMR 736 (check), TTB 7, ICP 16309 and ICP 3451 were found to have higher mean value than population mean with non significant bi and $S^{2} d_{i}$ values. None of the genotypes had stable performance. TJT 501 found higher pod bearing length. The genotypes viz., TJT 501, ICP 8700, ICP 6049 and ICP 3451 had the regression value more than unity, indicating its suitability to favourable environments. The genotypes viz., RVK 284, ICP 14832, BSMR 736 (check), TTB 7 and ICP 16309 had the regression value less than unity, it indicates suitable for poor environments. These findings are in accordance with Niranjan Kumar (2013).

The genotype ICP 13270 showed higher number of seeds per pod (4.80) while, ICP 8700 lesser number of seeds /pod (3.66) and population mean over three environments was 4.05. All the genotypes showed nonsignificant value for regression coefficient and deviation from regression. The genotypes viz., ICP 13270, ICP 13304, VKS 11/24-2, NDA 1, RVK 284, MAL 13, BSMR 736 (check), TJT 501, Bahar and ICP 6668 were found to have higher mean value than population mean with non significant bi and $\mathrm{S}^{2} \mathrm{~d}_{\mathrm{i}}$ values. The stability parameters for number of seeds per pod exhibited the genotypes RVK 284 and MAL 13 are stable across the environments, statistically regression $\left(b_{i}\right)$ value is equal to unity and $S^{2} d_{i}$ approaches to zero and ICP 13270 found higher number of seeds per pod. The genotypes viz., ICP 13304, VKS 11/24-2, NDA 1, BSMR 736 (check), TJT 501 and Bahar had the regression value more than unity, indicating its suitability to favourable environments. The genotypes viz., ICP 13270 and ICP 6668 had the regression value less than unity, it indicates suitable for poor environments. 
The genotype ICP 13270 showed highest pod length (4.90) while, ICP 9691 less pod length (3.82) and population mean over three environments was 4.31. All the genotypes showed non-significant value for regression coefficient and deviation from regression. The genotypes viz., ICP 13270, RVK 284, MAL 13, BSMR 736 (check), TTB 7, VKS 11/24-2, NDA 1, ICP 14832, ICP 12654 and TJT 501 were found to have higher mean value than population mean with non significant bi and $\mathrm{S}^{2} \mathrm{~d}_{\mathrm{i}}$ values. The stability parameters for pod length exhibited the genotype ICP 13270 as stable across the environments, statistically regression $\left(b_{i}\right)$ value is equal to unity and $S^{2} d_{i}$ approaches to zero. and ICP 13270 found maximum pod length. The genotypes viz., RVK 284, MAL 13, TTB 7, VKS 11/24-2 and TJT 501 had the regression value more than unity, indicating its suitability to favourable environments. The genotypes viz., BSMR 736 (check), NDA 1, ICP 14832 and ICP 12654 had the regression value less than unity, it indicates suitable for poor environments.

The genotype ICP 6668 showed higher number of pods per plant (168.99) while, ICP 8700 lesser number of pods/plant (103.33) and population mean over three environments was 135.03. All the genotypes showed nonsignificant value for regression coefficient and deviation from regression. The genotypes viz., ICP 6668, ICP 9691, VKS 11/24-2, BSMR 736 (check),ICP 13304, ICP 6049, ICP 3451, TJT 501, ICP 12654 and TTB 7 were found to have higher mean value than population mean with non significant bi and $\mathrm{S}^{2} \mathrm{~d}_{\mathrm{i}}$ values. None of the genotypes had stable performance. ICP 6668 found higher number of pods per plant. The genotypes viz., ICP 6668, ICP 9691, ICP 13304, ICP 6049 and ICP 3451 had the regression value more than unity, indicating its suitability to favourable environments. The genotypes viz., VKS
11/24-2, BSMR 736 (check), TJT 501, ICP 12654 and TTB 7 had the regression value less than unity, it indicates suitable for poor environments. These findings are in accordance with Shoran et al., (1981); Muthiah and Kalaimagal (2005); Vannirajan et al., (2007); Patel et al., (2009); Sreelakshmi et al., (2010); Thanki et al., (2010); Sawargaonkar et al., (2011) and Niranjan Kumar (2013)

The genotype ICP 6668 showed highest seed yield per plant (40.31) while, ICP 14832 less seed yield per plant (17.17) and population mean over three environments was 29.20. All the genotypes showed non-significant value for regression coefficient and deviation from regression. The genotypes viz., ICP 6668, BSMR 736 (check), ICP 6971, VKS 11/24-2, ICP 13304, ICP 13673, ICP 3451, ICP 9691 and NDA 1 were found to have higher mean value than population mean with non significant bi and $S^{2} d_{i}$ values. None of the genotypes had stable performance. ICP 6668 found highest seed yield per plant. The genotypes viz., ICP 6668, BSMR 736 (check), ICP 6971, ICP 13304, ICP 13673, ICP 3451 and ICP 9691 had the regression value more than unity, indicating its suitability to favourable environments. The genotypes viz., VKS 11/24-2 and NDA 1 had the regression value less than unity, it indicates suitable for poor environments. These findings are in accordance with Shoran et al., (1981); Muthiah and Kalaimagal (2005); Vannirajan et al., (2007); Patel et al., (2009); Sreelakshmi et al., (2010); Thanki et al., (2010); Sawargaonkar et al., (2011) and Niranjan Kumar (2013).

The genotype TJT 501 showed highest 100 seed weight (10.60) while, ICP 13304 less 100 seed weight (7.46) and population mean over three environments was 9.10. 
Table.1 Pooled MSS values for different quantitative traits over three environments

\begin{tabular}{|c|c|c|c|c|c|c|c|c|c|c|c|c|c|}
\hline $\begin{array}{l}\text { Source of } \\
\text { Variation } \\
\end{array}$ & DF & DFF & DM & PHT & PB & SB & PBL & NSPP & $\mathbf{P L}$ & NPPP & YLDPPT & 100SW & kg/ha \\
\hline Rep within Env. & 3 & 7.37 & 13.46 & 63.27 & 0.26 & 0.2 & 25.37 & $0.11 *$ & $0.36 * *$ & 15.58 & 15.78 & 0.37 & 97103.81 \\
\hline Varieties & 19 & $543.19 * *$ & $623.596 * *$ & $415.77 *$ & $4.62 *$ & $13.70 *$ & 46.37 & $0.24 * *$ & $0.34 * *$ & 873.9 & $84.71 *$ & $3.76 *$ & 193454.3 \\
\hline Env.+ (Var.* Env.) & 40 & 135.01 & 148.3 & $1602.90 * *$ & $4.77 * *$ & 10.48 & 127.1 & $0.37 * *$ & $0.62 * *$ & 1983.71 & $82.48 *$ & 1.6 & $402206.60 *$ \\
\hline Environments & 2 & $723.45 * *$ & $605.706 *$ & $27528.24 * *$ & $49.22 * *$ & $66.27 * *$ & $1024.57 * *$ & $5.06 * *$ & $10.0 * *$ & $11589.02 * *$ & $780.14 * *$ & 1.15 & $\begin{array}{l}5159995.00 \\
* *\end{array}$ \\
\hline Var.* Env. & 38 & 104.04 & 124.22 & 238.4 & 2.43 & 7.5 & 79.84 & $0.12 * *$ & $0.12 *$ & 1478.17 & 45.76 & 1.62 & 151796.7 \\
\hline $\begin{array}{l}\text { Environments } \\
\text { (Lin.) }\end{array}$ & 1 & $1446.91 * *$ & $1211.41 *$ & $55056.45 * *$ & $98.44 * *$ & $132.45 * *$ & $2049.1 * *$ & $10.1 * *$ & $20.1 * *$ & $23178.04 * *$ & $1560.2 * *$ & 2.3 & $0319990.0 * *$ \\
\hline Var.* Env.(Lin.) & 19 & 120.76 & 87.04 & 295.96 & 3.02 & 8.82 & 53.8 & $0.21 * *$ & $0.19 * *$ & 1858.58 & 58.71 & 1.79 & 110851.6 \\
\hline Pooled Deviation & 20 & $82.95 * *$ & $153.32 * *$ & $171.80 * *$ & 1.75 & $5.88 * *$ & $100.59 * *$ & 0.03 & 0.06 & $1042.86 * *$ & $31.17 * *$ & $1.38 * *$ & $83104.70 * *$ \\
\hline Pooled Error & 57 & 2.38 & 2.96 & 16.64 & 1.35 & 1.03 & 9.23 & 0.06 & 0.06 & 27.06 & 5.39 & 0.08 & 15435.68 \\
\hline Total & 59 & 266.44 & 301.35 & 1220.6 & 4.72 & 11.49 & 101.09 & 0.33 & 0.53 & 1626.31 & 83.2 & 2.29 & 334981.3 \\
\hline
\end{tabular}

$* \& * *$ significant at $5 \%$ and $1 \%$ level respectively

DFF : Days to 50 per cent flowering

DM : Days to maturity

PHT : Plant height $(\mathrm{cm})$

PB : Number of primary branches per plant

SB : Number of secondary branches per plant

PBL : Pod bearing length
NSPP : Number of seeds per pod

PL : Pod length $(\mathrm{cm})$

NPPP : Number of pods per plant

YLDPPT : Seed yield per plant

100SW : 100- seed weight $(\mathrm{g})$

$\mathrm{kg} / \mathrm{ha} \quad$ : seed yield $\mathrm{kg} / \mathrm{ha}$ 
Table.2 Mean and stability parameters in 20 genotypes of pigeon pea

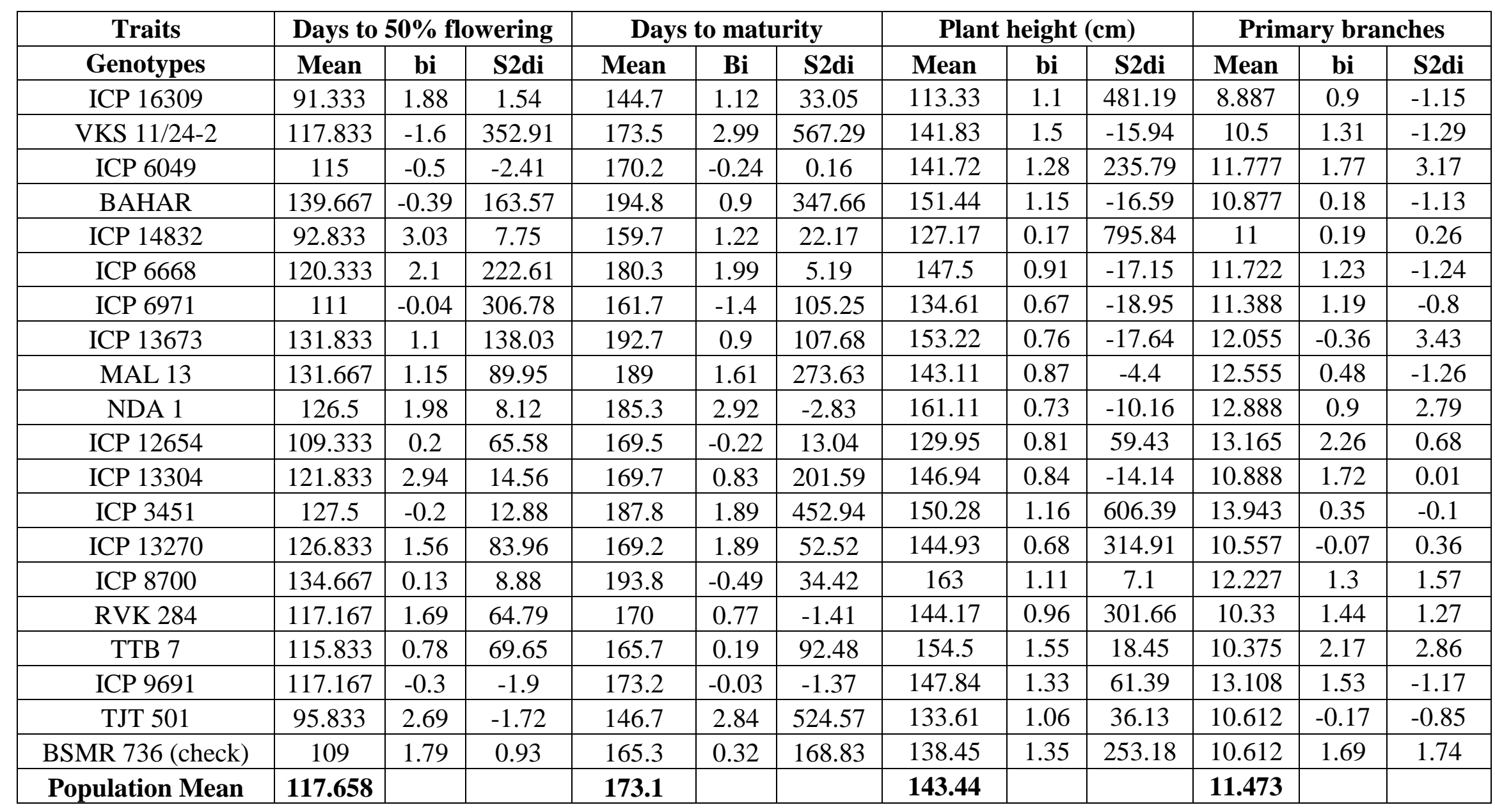


Table.3 Mean and stability parameters in 20 genotypes of pigeon pea

\begin{tabular}{|c|c|c|c|c|c|c|c|c|c|c|c|c|}
\hline \multirow{2}{*}{$\begin{array}{c}\text { Traits } \\
\text { Genotypes }\end{array}$} & \multicolumn{3}{|c|}{ Secondary Branches } & \multicolumn{3}{|c|}{$\begin{array}{c}\text { Pod bearing length } \\
(\mathrm{cm})\end{array}$} & \multicolumn{3}{|c|}{ Number of seeds /pod } & \multicolumn{3}{|c|}{ Pod length (cm) } \\
\hline & Mean & bi & S2di & Mean & $\mathbf{B i}$ & S2di & Mean & bi & S2di & Mean & bi & S2di \\
\hline ICP 16309 & 5.872 & 1.01 & -0.95 & 31.89 & 0.55 & 131.83 & 3.807 & -0.1 & -0.07 & 4.002 & 1.21 & 0 \\
\hline VKS 11/24-2 & 6.365 & 1.97 & -0.74 & 28.223 & 1.8 & 30.54 & 4.333 & 1.44 & -0.06 & 4.55 & 1.48 & -0.07 \\
\hline ICP 6049 & 5.222 & 1.77 & -0.98 & 35.333 & 1.18 & 1.03 & 3.835 & 0.25 & -0.04 & 3.933 & 0.93 & -0.03 \\
\hline BAHAR & 4.637 & -0.54 & 0.1 & 30 & 1.27 & -7.87 & 4.11 & 1.13 & 0.18 & 4.28 & 1.16 & -0.07 \\
\hline ICP 14832 & 4 & 0.31 & -0.75 & 33.472 & -0.2 & 78.72 & 3.972 & 0.53 & -0.04 & 4.402 & 0.7 & -0.07 \\
\hline ICP 6668 & 11.443 & 2.05 & 7.26 & 26.428 & 1.27 & 9.49 & 4.083 & 0.28 & -0.07 & 4.117 & 1.37 & -0.07 \\
\hline ICP 6971 & 10.005 & -1.59 & -0.95 & 26.39 & -0.34 & -9.46 & 3.748 & 1.16 & -0.07 & 3.945 & 0.95 & -0.08 \\
\hline ICP 13673 & 7.72 & 1.92 & 0.58 & 26.61 & 1.16 & 106.48 & 4.002 & 0.57 & -0.06 & 4.305 & 1.4 & -0.06 \\
\hline MAL 13 & 5.855 & 1.8 & -0.19 & 28.665 & 2.28 & 62.78 & 4.223 & 1.07 & -0.07 & 4.692 & 1.25 & -0.07 \\
\hline NDA 1 & 7.397 & 0.26 & -0.77 & 30.888 & 0.8 & 6.48 & 4.277 & 1.56 & -0.06 & 4.54 & 0.67 & 0.01 \\
\hline ICP 12654 & 8.222 & 2.37 & 36.19 & 24.833 & 0.85 & 132.65 & 3.75 & 1.22 & -0.02 & 4.365 & 0.45 & -0.08 \\
\hline ICP 13304 & 7.253 & 2.19 & 23.15 & 30.498 & 0.3 & 179.69 & 4.36 & 2.92 & 0.07 & 4.295 & -0.2 & -0.05 \\
\hline ICP 3451 & 7.555 & -0.36 & 3.57 & 31.798 & 1.28 & 170.93 & 3.723 & 1.07 & -0.07 & 3.917 & 0.92 & -0.08 \\
\hline ICP 13270 & 3.168 & -0.31 & 1.05 & 28.61 & 1.15 & 194.13 & 4.805 & 0.27 & 0.04 & 4.907 & 1.1 & -0.07 \\
\hline ICP 8700 & 5.198 & 0.64 & 3.6 & 36.055 & 2.53 & 34.42 & 3.667 & 0.57 & -0.06 & 3.862 & 0.87 & 0.06 \\
\hline RVK 284 & 5.015 & 0.31 & 5.94 & 36.723 & 0.31 & 495.39 & 4.223 & 1.07 & -0.07 & 4.867 & 1.45 & 0.02 \\
\hline TTB 7 & 4.298 & 0.91 & 0.07 & 32.5 & 0.81 & 33.01 & 4.055 & 1.12 & -0.02 & 4.56 & 1.47 & 0.4 \\
\hline ICP 9691 & 9.222 & 2.4 & -0.79 & 30.938 & 1.48 & 79.49 & 3.777 & 1.31 & -0.03 & 3.827 & 0.62 & 0.02 \\
\hline TJT 501 & 4.763 & 0.65 & 23.44 & 40.222 & 1.1 & 90.5 & 4.193 & 1.28 & -0.06 & 4.343 & 1.44 & -0.08 \\
\hline BSMR 736 (check) & 7.315 & 2.21 & -0.97 & 32.588 & 0.45 & -9.19 & 4.197 & 1.28 & -0.06 & 4.677 & 0.83 & -0.07 \\
\hline Population Mean & 6.526 & & & 31.133 & & & 4.057 & & & 4.319 & & \\
\hline
\end{tabular}


Table.4 Mean and stability parameters in 20 genotypes of pigeon pea

\begin{tabular}{|c|c|c|c|c|c|c|c|c|c|c|c|c|}
\hline \multirow{2}{*}{$\begin{array}{c}\text { Traits } \\
\text { Genotypes }\end{array}$} & \multicolumn{3}{|c|}{ Number of pods/plant } & \multicolumn{3}{|c|}{ Seed yield per plant(g) } & \multicolumn{3}{|c|}{100 seed weight $(\mathrm{g})$} & \multicolumn{3}{|c|}{ KG/HA } \\
\hline & Mean & bi & S2di & Mean & bi & S2di & Mean & bi & S2di & Mean & Bi & S2di \\
\hline ICP 16309 & 125.667 & 1.03 & 128.56 & 27.427 & 1.42 & -2.45 & 8.617 & 6.06 & -0.09 & 846.108 & 0.5 & -219104 \\
\hline VKS $11 / 24-2$ & 152.5 & 0.78 & -10.51 & 35.265 & 1.06 & 9.55 & 10.54 & -0.1 & 0.13 & 1347.218 & 1.59 & 625894 \\
\hline ICP 6049 & 145.682 & 1.03 & 215.18 & 24.247 & 1.34 & -5.15 & 8.343 & 5.28 & 3.34 & 1122.218 & 0.9 & -13418 \\
\hline BAHAR & 110.112 & -0.25 & 369.75 & 26.555 & 0.93 & 2.31 & 10.537 & -4.54 & 3.23 & 1198.883 & 1.16 & -9949 \\
\hline ICP 14832 & 124 & -0.45 & 9.18 & 17.173 & -0.25 & 2.77 & 8.012 & 5.38 & 0.4 & 1099.997 & 0.86 & 569829 \\
\hline ICP 6668 & 168.998 & 4.29 & 420.95 & 40.312 & 3.59 & 12.16 & 7.965 & -2.59 & 0.1 & 1520.272 & 0.85 & 1361830 \\
\hline ICP 6971 & 134.722 & 1.46 & 278.01 & 35.75 & 1.21 & 65.26 & 8.333 & 1.61 & 0.2 & 1456.105 & 0.66 & -11266 \\
\hline ICP 13673 & 120.61 & 1.98 & -18.07 & 32.323 & 1.51 & -2.58 & 10.342 & -4.79 & 2.4 & 1198.327 & 1.08 & -2276 \\
\hline MAL 13 & 115.525 & 1.81 & 1616.88 & 25.61 & 1.51 & 21.38 & 10.363 & -5.43 & 6.19 & 1101.662 & 0.92 & -17963 \\
\hline NDA 1 & 126.795 & 0.23 & 3391.06 & 29.742 & 0.03 & -5.64 & 9.468 & -2.28 & 0.8 & 1048.883 & 0.37 & 53628 \\
\hline ICP 12654 & 142.617 & 0.41 & 4055.86 & 28.082 & 0.41 & 0.33 & 8.697 & 7.15 & 0.13 & 1729.99 & 2.02 & 109163 \\
\hline ICP 13304 & 148.71 & 2.94 & 21.03 & 33.612 & 0.84 & 20.58 & 7.46 & 1.22 & 0.06 & 1151.103 & 0.78 & 43686 \\
\hline ICP 3451 & 143.183 & 1.28 & 81555.6 & 30.473 & 1.13 & 24.27 & 7.682 & 1.07 & -0.04 & 1162.775 & -0.1 & 309247 \\
\hline ICP 13270 & 129 & 0.59 & 93126.96 & 24.445 & 1.78 & 186.32 & 9.425 & 1.07 & 1.26 & 1502.773 & 1.03 & 43234 \\
\hline ICP 8700 & 103.333 & 1.95 & 203.99 & 25.167 & -0.38 & 46.14 & 8.358 & 2.1 & 5.22 & 1325.55 & 1.52 & 114592 \\
\hline RVK 284 & 119.943 & -0.62 & 78.36 & 28.223 & 0.18 & 4.78 & 10.08 & 6.02 & -0.08 & 1495.548 & 0.96 & -5536 \\
\hline TTB 7 & 136.182 & 0.71 & 74.57 & 28.615 & 0.93 & 6.06 & 9.99 & -1.76 & -0.05 & 1287.218 & 0.94 & 16185 \\
\hline ICP 9691 & 158.445 & 1.57 & 84.53 & 30.038 & 1.33 & 3.44 & 7.505 & 5.36 & 1.19 & 1756.103 & 1.3 & 88620 \\
\hline TJT 501 & 142.782 & -1.23 & 34695.81 & 24.8 & 0.27 & 111.76 & 10.605 & -2.2 & 1.15 & 1168.883 & 1 & 26497 \\
\hline BSMR 736 (check) & 151.945 & 0.5 & 29.9 & 36.165 & 1.17 & 3.89 & 9.78 & 1.34 & 0.16 & 1771.66 & 1.59 & -11179 \\
\hline Population Mean & 135.038 & & & 29.201 & & & 9.105 & & & 1314.564 & & \\
\hline
\end{tabular}


All the genotypes showed non-significant value for regression coefficient and deviation from regression. The genotypes viz., TJT 501, VKS 11/24-2, BAHAR, MAL 13, ICP 13673,RVK 284, TTB 7, BSMR 736 (check), NDA 1 and ICP 13270 were found to have higher mean value than population mean with non significant bi and $S^{2} d_{i}$ values. None of the genotypes had stable performance. TJT 501 found highest 100 seed weight. The genotypes viz., RVK 284, BSMR 736 (check) and ICP 13270 had the regression value more than unity, indicating its suitability to favourable environments. The genotypes viz., TJT 501, VKS 11/24-2, BAHAR, MAL 13, ICP 13673,TTB 7 and NDA 1 had the regression value less than unity, it indicates suitable for poor environments.

The genotype BSMR 736 (check) showed highest seed yield $\mathrm{kg} / \mathrm{ha}(1771.66 \mathrm{~kg})$ while, ICP 16309 less seed yield kg/ha (846.10) and population mean over three environments was $1314.56 \mathrm{~kg}$. All the genotypes showed nonsignificant value for regression coefficient and deviation from regression. The genotypes viz., BSMR 736 (check), ICP 9691, ICP 12654, ICP 6668, ICP 13270, RVK 284, ICP 6971, VKS 11/24-2 and ICP 8700 were found to have higher mean value than population mean with non significant bi and $\mathrm{S}^{2} \mathrm{~d}_{\mathrm{i}}$ values. The genotype ICP 13270 Well adapted to all the environments and none of the genotypes had stable performance. BSMR 736 (check) found highest seed yield $\mathrm{kg} / \mathrm{ha}$. The genotypes viz., BSMR 736 (check), ICP 9691, ICP 12654, VKS 11/24-2 and ICP 8700 had the regression value more than unity, indicating its suitability to favourable environments. The genotypes viz., ICP 6668, RVK 284 and ICP 6971 had the regression value less than unity, it indicates suitable for poor environments. These findings are in accordance with Shoran et al., (1981); Muthiah and Kalaimagal (2005); Vannirajan et al., (2007); Patel et al., (2009); Sreelakshmi et al., (2010); Thanki et al., (2010); Sawargaonkar et al., (2011) and Niranjan Kumar (2013).

In conclusion, from the present study it can be concluded that the genotype ICP-13270 were found to be a stable for pod length, ICP 9691 and ICP 12654 are on par with check for seed yield $\mathrm{kg} / \mathrm{ha}$ across the environments for rainfed conditions and these genotypes can also be used as a donor parent for generating new breeding material for development of variety (Tables 1-4). However, this needs to be verified by testing the breeding lines over the season and over the locations for one more year under rain fed condition.

\section{Acknowledgements}

The authors thank the Indian institute of pulse research (IIPR) Kanpur for the financial support.

\section{References}

Allard, R.W. and Bradshaw, A.D. 1964. Implication of genotype $\mathrm{X}$ environmental interaction in applied plant breeding. Crop Sci., 4: 503-505.

Balakrishnan, K. and Natarajaratnam, N. $1989 . \quad$ Genotype-environment interaction for yield components in pigeonpea [Cajanus cajan(L.) Millsp.] Madras Agri. J., 76: 365-370.

Eberhart, S.A. and Russell, W.A. 1966. Stability parameters for comparing varieties. Crop Sci., 6: 36-40.

Finlay, K.W. and Wilkinson, G.N. 1963. Analysis of adaptation in plant breeding programme. Australian J. Agri. Res., 14: 742-754.

Ghodke, M.K., Jahagirdar, J.E. and Makne, V.G. 1992. Phenotypic stability of newly developed pigeonpea genotypes. Indian J. Pulses Res., 5(2): 125-127.

Greilhuber, J. and Obermayer, R. 1998. Genome size variation in Cajanus cajan Fabaceae: a reconsideration. Plant Sys. 
Evol., 212: 135-141.

Hogh-jensen, H., Myaka, F.A., Sakala, W.D., Kamalongo, D., Ngwira, A., Vesterager, J.M., Odgaard, R and Adu-gyamfi, J.J. 2007. Yields and qualities of Pigeonpea varieties grown under smallholder farmers' conditions in eastern and southern Africa. African J. Agri. Res., 2: 269-278.

Muthiah, A.R. and Kalaimagal, T. 2005. Stability analysis in hybrid pigeonpea. Indian J. Pulses Res., 18(1): 76-79.

Niranjanakumara, B. 2013. Stability analysis for yield and its attributing traits in advanced genotypes of pigeonpea [Cajanus cajana. (L) Millsp.]M. Sc. (Agri.) Thesis, UAS Raichur Karnataka India.

Patel, P.T., Chauhan, R.M., Parmar, L.D and Tikka, S.B.S. 2009. Phenotypic stability of yield and related traits in pigeonpea. Leg. Res., 32(4): 235-239.

Sawargaonkar, S.L., Saxena, K.B., Madrap, I.A. and Rathore, A. 2011. Stability analysis of yield and related traits in pigeonpea hybrids. J. Food Leg., 24(3): 184-193.

Shoran, J.B., Pandya, B.P. and Gautam, P.L. 1981. Genotype $\times$ environment interaction analysis in pigeonpea. Crop
Impr., 8: 33-36.

Singh, V. 1984. Mechanical diallel and stability analysis in pigeonpea [Cajanus cajan (L.) Millsp.].M.Sc. (Agri.) Thesis, Haryana Agricultural UniversityHissar India.

Sreelakshmi, C., Sameer Kumar, C.V. and Shivani, D. 2010. Genetic analysis of yield and its component traits in drought tolerant genotypes of Pigeonpea (Cajanus cajan (L.) Millsp.). Elec. J. Pl. Breeding, 1(6): 1488-1491.

Thanki, H.P., Sawargaonkar, S.L. and Hudge, B.V. 2010. Genotype x environment interaction for biometrical traits in pigeonpea (Cajanus cajanL. Millsp.) under varying spacing. Elec. J. $\mathrm{Pl}$. Breeding, 1(4): 925-928.

Van der and Messen, L.J.G. 1980. India is the native home of the pigeonpea. In: Arends JC BoelmaGde Grant CT Leeuwaenberg AJM. (Eds) Libergratularious in Honrem HCD.de Wit. Agricultural University Miscellan Paper, 19: 257-262.

Vanniarajan, C., Rangasamy, P. and Nepolean, T. 2007. Stable and unstable Pigeonpea genotypes for yield versus component characters. Pl. Arch., 7(1): 427-428.

\section{How to cite this article:}

Ramesh, S. Muniswamy and Praveenkumar, B. 2017. Stability Analysis for Yield and its Components in Pigeonpea [Cajanus cajan (L.) Mill sp.] Under Rainfed Conditions. Int.J.Curr.Microbiol.App.Sci. 6(5): 1134-1144. doi: https://doi.org/10.20546/ijcmas.2017.605.123 